BMJ

Open

Gastroenterology

\section{The first cases of collagenous sprue successfully treated with thioguanine} Tom van Gils, ${ }^{1}$ Tine van de Donk, ${ }^{1}$ Gerd Bouma, ${ }^{1}$ Foke van Delft, ${ }^{1}$
E Andra Neefjes-Borst, ${ }^{2}$ Chris J J Mulder, ${ }^{1}$
To cite: van Gils T, van de Donk T, Bouma G, et al. The first cases of collagenous sprue successfully treated with thioguanine. BMJ Open Gastro 2016:3:e000099. doi:10.1136/bmjgast-2016000099

Received 29 April 2016 Revised 10 May 2016 Accepted 12 May 2016
${ }^{1}$ Department of Gastroenterology and Hepatology, VU University Medical Center, Amsterdam, The Netherlands

2Department of Pathology, VU University Medical Center, Amsterdam, The Netherlands

Correspondence to

Tom van Gils;

t.vangils@vumc.nl

\section{ABSTRACT}

Objective: Collagenous sprue (CS) is a rare form of small bowel enteropathy characterised by a thickened basement membrane and is, in most of the literature, reported as part of coeliac disease. Multiple treatment strategies are suggested in CS, but there is no standardised therapy. The aim of this series is to describe 4 cases of CS and to propose thioguanine (6-TG) treatment.

Design: We reviewed 4 cases of CS. Data were obtained from our prospective database of patients referred to our coeliac centre. Evaluation of small bowel biopsies was performed by an expert pathologist

Results: None of the patients had ever had coeliacspecific antibodies, and all were negative for HLA-DQ2 and HLA-DQ8 phenotype. Three patients were treated with a combination of 6-TG and budesonide, and 1 patient received 6-TG only. All patients improved remarkably. Normalisation of the thickened basement membrane was found in 2 patients and complete histological improvement including full recovery of villi was found in 1 patient. In the third patient, the thickened basement membrane was only very focally recognised. The thickened membrane persisted in the last patient, probably because of the short time of follow-up.

Conclusions: CS should be separated from coeliac disease. Based on the lack of typical HLA phenotyping and the absence of coeliac-specific antibodies, there seems to be no relation with coeliac disease in these 4 cases. A promising treatment option might be 6-TG with or without budesonide. Research in a larger cohort is needed to standardise treatment for CS.

\section{INTRODUCTION}

Collagenous sprue (CS) is a rare form of small bowel enteropathy, first described in 1947 by Schein. ${ }^{1}$ The term CS was introduced in 1970 by Weinstein et al. ${ }^{2}$ Only a limited number of 70 patients have been reported. ${ }^{3}$ Well-defined diagnostic criteria for CS are not yet available. Upper endoscopic evaluation of patients with CS often shows unspecific anomalies such as slight mucosal scalloping. ${ }^{4} \mathrm{CS}$ is characterised by a

\section{Summary box}

What is already known about this subject?

- Collagenous sprue is a rare form of small bowel enteropathy.

- The degree of histological abnormality in collagenous sprue does not correlate with the severity of the clinical symptoms.

- Main symptoms of collagenous sprue are unintentional weight loss and diarrhoea.

What are the new findings?

- Collagenous sprue should be seen as a separate enteropathy, apart from coeliac disease.

- Thioguanine with or without budesonide might be a promising treatment option in collagenous sprue.

- Thioguanine with or without budesonide seems to be a safe treatment option in collagenous sprue.

How might it impact on clinical practice in the foreseeable future?

- Clinicians should consider collagenous sprue also in the absence of coeliac disease. Thioguanine with or without budesonide seems to be a good treatment strategy in collagenous sprue, which is important to know because the condition currently has no established treatment protocol.

patchy and irregular thickened basement membrane of the small bowel. Cut-off values for this thickened collagen band vary between different studies from $10 \mu \mathrm{m}$ to $20 \mu \mathrm{m}$, and collagen thickness up to $260 \mu \mathrm{m}$ has been described. ${ }^{3}{ }^{5} 6$ In addition to a thickened collagenous band, villous atrophy, intraepithelial lymphocytosis, detachment of the epithelium and entrapment of capillaries, inflammatory cells and fibroblasts within the collagen band can be found. ${ }^{6-8}$ Increased numbers of plasma cells, neutrophils and/or eosinophils can be present in the lamina propria. Areas of mucosal ulceration have been described as well. ${ }^{6}{ }^{9}$ Main symptoms are unintentional weight loss, hypoalbuminaemia, diarrhoea, bloating and 
anaemia. Mean age at diagnosis is 59 years with women two times more likely to be affected than men. ${ }^{6} 10$

Little is known about the aetiology and pathogenesis of this disease. Most authors have suggested that there is a relationship between coeliac disease (CD) and the occurrence of CS. The majority of the information about this condition results from individual case reports; larger observational studies have not yet been performed. Freeman ${ }^{11}$ suggested that CS is an inflammatory mucosal disease that may represent a more generalised inflammatory response to a diverse group of (autoimmune) disorders, such as Sjögren's syndrome or systemic lupus erythematosus. ${ }^{569}$ A relationship with the usage of nonsteroidal anti-inflammatory drugs (NSAIDs), olmesartan and clofazimine, has also been suggested..$^{5} 6$ 12-14

Case reports have described a variety of therapeutic strategies for CS, but there is still no generally accepted treatment protocol. Maguire et at $t^{6}$ described that half of the patients responded to treatment with steroids and a gluten-free diet (GFD). Many patients, however, did have a devastating course and died from malnutrition. ${ }^{6} 7$

Thioguanine (6-TG) is a purine analogue that belongs to the thiopurine family of drugs that also include mercaptopurine and azathioprine. It is a well-known and well-absorbed drug used in inflammatory bowel disease (IBD) in dosages of only $0.2-0.3 \mathrm{mg} / \mathrm{kg} .{ }^{15}$ Additionally, 6-TG has successfully been used in patients with refractory CD type $\mathrm{I}^{16}$ One of the 6-TG metabolites is 6-thioguanine-triphosphate, which is part of the 6-thioguaninenucleotides (6-TGN), and induces T-cell apoptosis, using a mitochondrial pathway. ${ }^{17}$ We hypothesise a role for $\mathrm{T}$ cells in CS. In this article, we describe four patients with CS, and demonstrate that treatment with 6-TG may be an attractive treatment option for this disease.

\section{METHODS}

In the database of our dedicated small bowel unit, four patients with CS treated with 6-TG were recognised. Both clinical charts were reviewed and an expert pathologist specialised in the gastrointestinal tract (EAN-B) reviewed the histological features of the patient's duodenal biopsies.

This study was presented to the Medical Ethics Review Committee of VU University Medical Center. They confirmed that the Medical Research Involving Human Subjects Act (WMO) does not apply to this study and that an official approval of this study by the committee is not required.

\section{RESULTS}

Four patients with CS were identified who were diagnosed between 2011 and 2015, based on histological analysis of their duodenal biopsies. Follow-up varied between 4 and 40 months. Table 1 provides an overview of all the histological findings at baseline and during follow-up in the four patients. Figure 1 shows histological slides of CS. Notably, all four patients were negative for human leukocyte antigen-DQ2 and human leucocyte antigen (HLA)-DQ8, and serology showed no evidence of CD. None of the patients had used medication associated with the development of villous atrophy, such as olmesartan or NSAIDs, at time of diagnosis. ${ }^{18}$

\section{Case 1}

Patient 1, a 77-year-old woman, presented with fatigue, unintentional weight loss of $10 \mathrm{~kg}$ in 4 months, loss of appetite, abdominal pain and varying stool consistency. Her medical history showed aorta valve stenosis.

Duodenal biopsies showed subtotal villous atrophy and a basement membrane ranging between 12 and $14 \mu \mathrm{m}$. Colonoscopy showed no abnormalities; biopsies showed no signs of collagenous colitis. Initially, the patient was treated with a GFD for her CS, without any improvement. Treatment was then started with budesonide slow release (SR) $3 \mathrm{mg}$ three times a day, which was decreased after 4 months to $6 \mathrm{mg}$ per day. Initially, her stool was once a day with a mushy consistence. Since she had epigastric pain and the collagenous band persisted, treatment with 6-mercaptopurine $50 \mathrm{mg}$ was initiated. Knowledge about the safety of 6-TG as previous described made us switch to 6-TG $18 \mathrm{mg}$ a day, which she took 5 days a week. After 1 year of treatment, she received $10 \mathrm{mg}$ 6-TG three times a week together with $3 \mathrm{mg}$ budesonide SR daily, and did not experience further symptoms. After 4 years of follow-up, biopsies still showed mild villous atrophy, however, the membrane thickness normalised.

\section{Case 2}

A 79-year-old man presented with watery diarrhoea, fatigue, poor condition and unintentional weight loss. His medical history was otherwise unremarkable.

Laboratory investigations showed anaemia, hypocalcaemia and hypoalbuminaemia. Histological analysis of duodenal biopsies showed total villous atrophy, chronic inflammation and a thickened basement membrane of $34.2 \mu \mathrm{m}$. There was no intraepithelial lymphocytosis. Based on these findings, he was diagnosed with CS.

Initially, the patient was treated with a GFD because of CS without any result. He was treated with $18 \mathrm{mg}$ 6-TG a day in combination with $9 \mathrm{mg}$ budesonide SR daily for 10 months. Follow-up showed an improved general condition, normalisation of the faecal pattern, weight gain and improved laboratory findings. Endoscopy was repeated and, despite the improved general condition, duodenal biopsies still showed a basement membrane of $32.3 \mu \mathrm{m}$ and total villous atrophy.

After 1.5 year, the patient decided to stop the medication because of side effects, including nausea. Two months after he stopped his medication, he lost $4 \mathrm{~kg}$ and diarrhoea returned together with nausea. A few weeks after 6-TG (10 mg a day) and budesonide SR (3 mg three times a week) was restarted, symptoms disappeared again. Thirty months after initial diagnosis, the thickened basement membrane nearly disappeared 


\begin{tabular}{|c|c|c|c|c|c|c|c|c|c|c|}
\hline Case & Gender & $\begin{array}{l}\text { Follow-up } \\
\text { (months) }\end{array}$ & $\begin{array}{l}\text { Age } \\
\text { (years) }\end{array}$ & Treatment & $\begin{array}{l}\text { Clinical } \\
\text { evaluation }\end{array}$ & $\begin{array}{l}\text { Maximum } \\
\text { thickness } \\
\text { of BM }(\mu \mathrm{m})\end{array}$ & $\begin{array}{l}\text { Villous } \\
\text { atrophy }\end{array}$ & $\begin{array}{l}\text { IEL (per } 100 \\
\text { enterocytes) }\end{array}$ & $\begin{array}{l}\text { Epithelial } \\
\text { detachment }\end{array}$ & $\begin{array}{l}\text { LP vessels } \\
\text { entrapped in } \\
\text { basement membrane }\end{array}$ \\
\hline \multirow[t]{4}{*}{1} & \multirow[t]{4}{*}{$\mathrm{F}$} & Baseline & 77 & & & 14 & Subtotal & 12 & $\begin{array}{l}>10 \% \text { of } \\
\text { surface }\end{array}$ & Present \\
\hline & & 11 & & Budesonide & $\begin{array}{l}\text { No } \\
\text { improvement }\end{array}$ & 21 & Total & 10 & $\begin{array}{l}<10 \% \text { of } \\
\text { surface }\end{array}$ & Present \\
\hline & & 18 & & 6-MP & $\begin{array}{l}\text { Small } \\
\text { improvement }\end{array}$ & 18 & Total & 12 & $\begin{array}{l}>10 \% \text { of } \\
\text { surface }\end{array}$ & Present \\
\hline & & 40 & & $\begin{array}{l}\text { Budesonide } \\
\text { and } 6-T G\end{array}$ & Improvement & 2 & Mild & 6 & $\begin{array}{l}<10 \% \text { of } \\
\text { surface }\end{array}$ & Absent \\
\hline \multirow[t]{3}{*}{2} & \multirow[t]{3}{*}{$M$} & Baseline & 79 & & & 34 & Total & 10 & $100 \%$ & Present \\
\hline & & 9 & & $\begin{array}{l}\text { Budesonide } \\
\text { and } 6-T G\end{array}$ & Improvement & 32 & Total & 24 & $25-50 \%$ & Present \\
\hline & & 30 & & $\begin{array}{l}\text { Budesonide } \\
\text { and 6-TG }\end{array}$ & Improvement & $21^{*}$ & Subtotal & 14 & $>50 \%$ & Present \\
\hline \multirow[t]{2}{*}{3} & \multirow[t]{2}{*}{$\mathrm{F}$} & Baseline & 88 & & & 21 & Total & 12 & $\begin{array}{l}>10 \% \text { of } \\
\text { surface }\end{array}$ & Present \\
\hline & & 10 & & $\begin{array}{l}\text { Budesonide } \\
\text { and } 6-T G\end{array}$ & Improvement & 2 & None & 4 & Absent & Absent \\
\hline \multirow[t]{2}{*}{4} & \multirow[t]{2}{*}{$\mathrm{F}$} & Baseline & 76 & & & 19 & Total & 32 & $\begin{array}{l}<10 \% \text { of } \\
\text { surface }\end{array}$ & Present \\
\hline & & 3 & & 6-TG & Improvement & 23 & Total & $14 \dagger$ & $\begin{array}{l}>10 \% \text { of } \\
\text { surface }\end{array}$ & Present \\
\hline
\end{tabular}

*Very focal.

tAlso some intraepithelial eosinophils.

6-MP, 6-mercaptopurine; 6-TG, 6-thioguanine; BM, basement membrane; F, female; IEL, intraepithelial lymphocytes; LP, lamina propria; M, male. 

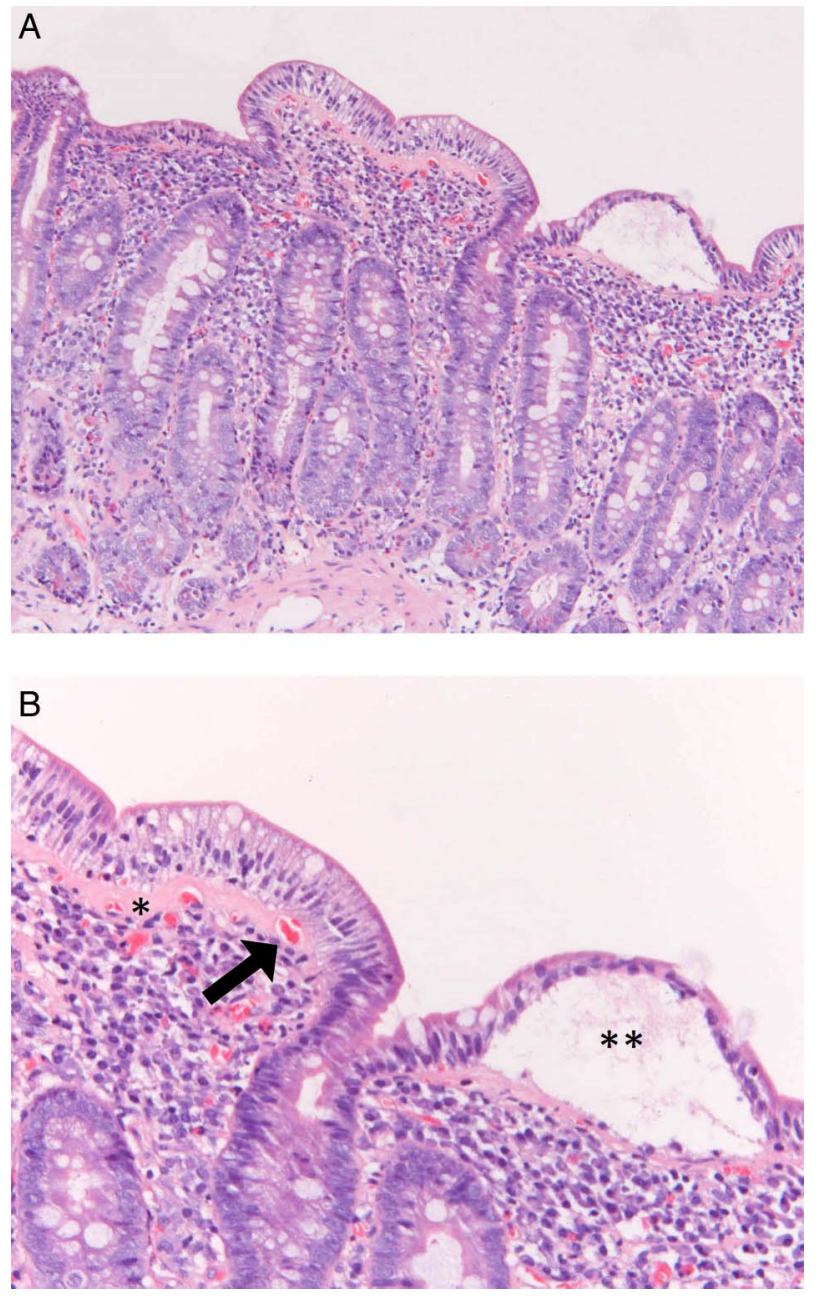

Figure 1 H\&E stain of a duodenal biopsy showing collagenous sprue. The subepithelial collagen band is slightly thickened $\left({ }^{*}\right)$. Villous atrophy, epithelial detachment $\left({ }^{* *}\right)$ and lamina propria vessels entrapped in the collagen band (black arrow) are also shown (original magnification $A \times 100, B$ $\times 200)$.

and villous architecture improved from total to subtotal villous atrophy.

\section{Case 3}

An 88-year-old woman presented with a poor general condition, nausea, vomiting, weight loss and an alternating faecal pattern, ranging from constipation to watery diarrhoea. She had, two years prior, been diagnosed with seronegative $\mathrm{CD}$, based on duodenal subtotal villous atrophy. Since then, she had been on a GFD, but with poor compliance.

Repeated coeliac serology in our clinic showed no antibodies against tissue transglutaminase and endomysium and no IgA deficiency. HLA-DQ2 and HLA-DQ8 were both negative, so the diagnosis of $\mathrm{CD}$ was rejected in retrospect. Further medical history was not relevant. Duodenal biopsies showed total villous atrophy, patchy intraepithelial lymphocytosis and a basement membrane thickness of $21 \mu \mathrm{m}$, so she was diagnosed with CS.
She was treated with $18 \mathrm{mg}$ 6-TG a day for 5 days a week and $9 \mathrm{mg}$ budesonide SR daily. After 1 month, 6-TG was reduced to $10 \mathrm{mg}$ daily and budesonide was stopped. After 6 months, the patient's weight loss and consistency of stool improved. One year after initial treatment, upper endoscopy was performed. The biopsies showed no abnormalities; a fully recovered villous architecture and no thickened basement membrane were found. Currently, this patient still receives $6-\mathrm{TG} 10 \mathrm{mg}$ a day together with budesonide SR $3 \mathrm{mg}$ three times a week.

\section{Case 4}

A 76-year-old woman presented with nausea, constipation, weight loss of $18 \mathrm{~kg}$ in 1.5 year and poor physical performance. There was an extensive medical history, including some episodes of small bowel inflammation otherwise not specified.

Duodenal biopsies showed total villous atrophy, intraepithelial lymphocytosis and a thickened basement membrane of $19 \mu \mathrm{m}$, although biopsies from 9 years prior showed no abnormalities. The patient was diagnosed with CS. Colonoscopy with biopsies was also performed. Analysis of these biopsies showed collagenous colitis. Evaluation of duodenal biopsies after 3 months of treatment with 6-TG $20 \mathrm{mg}$ a day showed a decrease of intraepithelial lymphocytes, but still displayed a thickened basement membrane of $17-23 \mu \mathrm{m}$ and total villous atrophy. Clinically, the patient improved, she increased in weight and gained her appetite back.

\section{DISCUSSION}

The aetiology and pathogenesis of CS are still not understood. CS mainly affects middle-aged to elderly women, but cases of CS in infants have also been reported. ${ }^{19} 20$ As shown in this case series, patients present with symptoms of malabsorption. Robert et $a t^{21}$ showed that the degree of histological abnormality in CS does not correlate with the severity of the clinical symptoms, which we can confirm.

Previous studies reported a possible relationship between CD and the occurrence of CS. ${ }^{2} 2122$ However, this relationship remains controversial. Nearly all patients affected with $\mathrm{CD}$ are positive for HLA-DQ2 or HLA-DQ8. ${ }^{23}$ Evaluating the cases in this study, all four patients were negative for HLA-DQ2 and HLA-DQ8, with negative coeliac serology, which proves that CS can occur in the absence of CD. This showed that CS can either be the result or end point of multiple disease entities as reported earlier, or idiopathic as in these cases.

So far, there are no established treatment protocols for CS. A variety of therapeutic options have been described, including a GFD, milk-free diet, corticosteroids (including budesonide SR), sulfasalazine, cyclosporine, azathioprine, high-dose proton pump inhibitor and monoclonal tumour necrosis factor- $\alpha$ antibody, ${ }^{4-6} 92425$ but no adequate therapy has yet been found. Failure of any response to treatment could lead to malabsorption, small bowel ulceration, perforation and T-cell and B-cell lymphoma. ${ }^{6} 81$ 
This is the first study to describe CS treatment with 6-TG. All four patients were treated with 6-TG, three of them also received budesonide SR. Three of four patients improved histologically (villous atrophy and basement thickness) and all patients improved clinically (table 1). One of these patients even showed complete histological response and another had reoccurring symptoms after stopping 6-TG. This suggests that 6-TG, with or without budesonide SR, might be a therapeutic option in CS. At least one positive experience with another thiopurine, azathiopurine, together with steroids is described in the literature, with clinical and total histological improvement. ${ }^{6}$ As we observed four patients with different time intervals between start of therapy and clinical and histological recovery, it is difficult to suggest a standard treatment period based on our findings.

It is important to notice that 6-TG might have a hepatotoxic effect. In particular, it has been associated with the development of nodular regenerative hyperplasia, veno-occlusive disease and non-cirrhotic portal hypertension. ${ }^{26}$ However, low dosages of 6-TG are safe in our experience, with at least 1500 patients with IBD using this drug for maintenance. ${ }^{15}$ In all our patients, serum levels of 6-TGN were monitored and never elevated. Transaminase and thrombocytes were normal in all patients, and $\gamma$-glutamyl transferase and alkaline phosphatase slightly elevated in two patients, during follow-up.

In conclusion, the aetiology and pathophysiology of CS remains poorly understood. The relationship between $\mathrm{CD}$ and $\mathrm{CS}$ is controversial, but with our current experience and knowledge, we would suggest that CS is a separate entity, apart from CD. There is no established treatment protocol available. Multiple therapeutic options have been described for this rare disease, showing only limited results. However, in this study, treatment with 6-TG with or without budesonide suggested good clinical and histological results. The use of 6-TG could be a safe treatment option in CS.

Contributors TvG and TvdD were involved in acquisition, analysis and interpretation of the data, and drafting the work. GB was involved in interpretation of the data and revising the manuscript for important intellectual content. FvD was involved in acquisition of the data and revising the manuscript for important intellectual content. EAN-B was involved in analysis and interpretation of the data (histological revision), and revising the manuscript for important intellectual content. CJJM was involved in concept and design of the work, acquisition, analysis and interpretation of the data, and revising the manuscript for important intellectual content.

Competing interests None declared.

Patient consent Obtained.

Provenance and peer review Not commissioned; externally peer reviewed.

Data sharing statement No additional data are available.

Open Access This is an Open Access article distributed in accordance with the Creative Commons Attribution Non Commercial (CC BY-NC 4.0) license, which permits others to distribute, remix, adapt, build upon this work noncommercially, and license their derivative works on different terms, provided the original work is properly cited and the use is non-commercial. See: http:// creativecommons.org/licenses/by-nc/4.0/

\section{REFERENCES}

1. Schein J. Syndrome on non tropical sprue with hitherto undescribed lesions of the intestine. Gastroenterology 1947;8:438-60.

2. Weinstein WM, Saunders DR, Tytgat GN, et al. Collagenous spruean unrecognized type of malabsorption. $N$ Engl J Med 1970;283:1297-301.

3. Zhao X, Johnson RL. Collagenous sprue: a rare, severe small-bowel malabsorptive disorder. Arch Pathol Lab Med 2011;135:803-9.

4. Soendergaard C, Riis LB, Nielsen $\mathrm{OH}$. Collagenous sprue: a coeliac disease look-alike with different treatment strategy. BMJ Case Rep 2014;2014:pii: bcr2014203721.

5. Rustagi T, Rai M, Scholes JV. Collagenous gastroduodenitis. J Clin Gastroenterol 2011;45:794-9.

6. Maguire AA, Greenson JK, Lauwers GY, et al. Collagenous sprue: a clinicopathologic study of 12 cases. Am J Surg Pathol 2009;33:1440-9.

7. Rubio-Tapia A, Talley NJ, Gurudu SR, et al. Gluten-free diet and steroid treatment are effective therapy for most patients with collagenous sprue. Clin Gastroenterol Hepatol 2010;8:344-9.

8. Freeman HJ. Collagenous sprue. Can J Gastroenterol 2011;25:189-92.

9. Gopal P, McKenna BJ. The collagenous gastroenteritides: similarities and differences. Arch Pathol Lab Med 2010;134:1485-9.

10. Nielsen $\mathrm{OH}$, Riis LB, Danese $\mathrm{S}$, et al. Proximal collagenous gastroenteritides: clinical management. A systematic review. Ann Med 2014;46:311-17

11. Freeman HJ. Collagenous mucosal inflammatory diseases of the gastrointestinal tract. Gastroenterology 2005;129:338-50.

12. Rubio-Tapia A, Herman ML, Ludvigsson JF, et al. Severe sprue like enteropathy associated with olmesartan. Mayo Clin Proc 2012;87:732-8.

13. Vasant DH, Hayes S, Bucknall R, et al. Clinical and histological resolution of collagenous sprue following gluten-free diet and discontinuation of non-steroidal anti-inflammatory drugs (NSAIDs). BMJ Case Rep 2013;2013:pii: bcr2013200097.

14. Nielsen JA, Steephen A, Lewin M. Angiotensin-II inhibitor (olmesartan)-induced collagenous sprue with resolution following discontinuation of drug. World J Gastroenterol 2013;19:6928-30.

15. Mulder CJ, van Asseldonk DP, de Boer NK. Drug rediscovery to prevent off-label prescription reduces health care costs: the case of tioguanine in the Netherlands. J Gastrointestin Liver Dis 2014;23:123-5.

16. Tack GJ, van Asseldonk DP, van Wanrooij RL, et al. Tioguanine in the treatment of refractory coeliac disease-a single centre experience. Aliment Pharmacol Ther 2012;36:274-81.

17. de Boer NK, van Bodegraven AA, Jharap B, et al. Drug insight pharmacology and toxicity of thiopurine therapy in patients with IBD. Nat Clin Pract Gastroenterol Hepatol 2007;4:686-94.

18. Bhat N, Anupama NK, Yelsangikar A, et al. Olmesartan-related sprue-like enteropathy. Indian $J$ Gastroenterol 2014;33:564-7.

19. Jimbo K, Aoyagi Y, Tanaka M, et al. Collagenous sprue in a 3-month-old infant. Pediatr Int 2015;57:e18-22.

20. Billiemaz K, Robles-Medranda C, Le GC, et al. A first report of collagenous gastritis, sprue, and colitis in a 9-month-old infant: 14 years of clinical, endoscopic, and histologic follow-up. Endoscopy 2009;41(Suppl 2):E233-4.

21. Robert ME, Ament ME, Weinstein WM. The histologic spectrum and clinical outcome of refractory and unclassified sprue. Am J Surg Pathol 2000;24:676-87.

22. Cellier C, Delabesse E, Helmer C, et al. Refractory sprue, coeliac disease, and enteropathy-associated T-cell lymphoma. French Coeliac Disease Study Group. Lancet 2000;356:203-8.

23. Hadithi M, von Blomberg BM, Crusius JB, et al. Accuracy of serologic tests and HLA-DQ typing for diagnosing celiac disease. Ann Intern Med 2007;147:294-302.

24. Freeman HJ, Davis JE, Myers DM. Complete histological resolution of collagenous sprue. Can J Gastroenterol 2004;18:333-6.

25. Vesoulis Z, Lozanski G, Ravichandran P, et al. Collagenous gastritis: a case report, morphologic evaluation, and review. Mod Pathol 2000;13:591-6.

26. Dubinsky MC, Vasiliauskas EA, Singh $\mathrm{H}$, et al. 6-thioguanine can cause serious liver injury in inflammatory bowel disease patients. Gastroenterology 2003;125:298-303.

27. Seiderer J, Zech CJ, Reinisch W, et al. A multicenter assessment of liver toxicity by MRI and biopsy in IBD patients on 6-thioguanine. J Hepatol 2005;43:303-9. 